\title{
The Effectiveness of Nursing Intervention for Patients with Claustrophobia in MR Examination
}

\author{
Guiqing Dong, Bing Zhao, Kai Deng* \\ CT-MR Division, Shandong Provincial Qianfoshan Hospital, Jinan, China \\ Email: *calab2a@tom.com
}

How to cite this paper: Dong, G.Q., Zhao, B. and Deng, K. (2017) The Effectiveness of Nursing Intervention for Patients with Claustrophobia in MR Examination. Yangtze Medicine, 1, 104-108.

https://doi.org/10.4236/ym.2017.12010

Received: February 27, 2017

Accepted: June 19, 2017

Published: June 22, 2017

Copyright (c) 2017 by authors and Scientific Research Publishing Inc. This work is licensed under the Creative Commons Attribution International License (CC BY 4.0).

http://creativecommons.org/licenses/by/4.0/ (c) (†) Open Access

\begin{abstract}
Objective: To evaluate the effectiveness of a nursing intervention for patients with claustrophobia in MR examination. Methods: This study included 40 claustrophobic patients who underwent MR examination from March 2013 to May 2015 in our hospital. These patients were randomly divided into two groups; each group had 20 patients. Among them, usual care was taken in one group (control group) and nursing intervention was added on the basis of usual care in another group (observation group). The patient's psychological state and MR successful rate were compared between these two groups. Results: In control group and observation group, the scores of anxiety were $46.20 \pm 3.07,37.50 \pm 2.54$, respectively. The scores of depression were $44.30 \pm$ $2.54,37.70 \pm 2.15$. MR successful rates were $35.00 \%$ and $90.00 \%$, respectively. There were significant differences in these two groups $(P<0.05)$. Conclusion: Effective nursing interventions can improve patient's psychological state and MR successful rate for claustrophobic patients.
\end{abstract}

\section{Keywords}

Claustrophobia, Nursing Intervention, MR Examination

\section{Introduction}

Claustrophobia is a kind of psychological disease. In confined space, patients would have serious symptoms, such as fear and anxiety. It might be caused by many reasons, such as life experience, personality factors and mental stress [1] [2]. Owing to lack of self-control of the patients, many clinical examinations could not be operated well. The aim of this study was to evaluate the effectiveness of a nursing intervention for patients with claustrophobia in MR examina- 
tion.

\section{Materials and Methods}

\subsection{Basic Information}

40 patients with claustrophobia confirmed by professional psychological doctors were selected in our hospital from March 2013 to May 2015. The patients were randomly divided into two groups: a control group and observation group. In control group, 11 patients were male, and 9 patients were female, with age from 18 to 56 years old ( $34.28 \pm 5.46$ years). In observation group, 12 patients were male, and 8 patients were female, with age from 19 to 57 years old (34.32 \pm 5.51 years). The difference of basic information between these two groups was not significant $(\mathrm{P}>0.05)$.

MR imaging was performed using a 3-T MR system (Siemens Magnetom Skyra 3.0T) with an 8-channal phased-array coil. Routine head MR images were acquired as follows: T2-weighted imaging in the axial plane, T2-flair weighted imaging in axial plane, T1-weighted imaging in axial plane, T2-weighted imaging in saggital plane. The scan time was about ten minutes.

\subsection{Nursing Methods}

In control group, patients were adopted by routine nursing. Informed consents were taken before the examination. Patients were guided to get rid of objects which could affect inspection effects and helped to adjust to the right position. Then patients were trained to hold breathing, given anti-anxiety agents. Besides the basic routine nursing, strengthened nursing interventions were given in observation group. The detailed methods were as follows:

\subsubsection{Health Education}

Introduced the importance of MRI examination, discussed the relationship between psychological factors and diseases, alleviated patients' fear of examination and helped patients cooperate with examination voluntarily.

\subsubsection{Environmental Nursing}

The light in examining room was adjusted to a downy and bright degree, with goods putting in order. The ventilation system was kept routinely, and the temperature and humidity were accommodated to the right degree. Keeping examining table clean and room warm with pads and blankets prepared. These steps could make patients feel comfortable and reduce their fear.

\subsubsection{Mental Nursing and Family Support}

Taken patients and their families to observe the magnetic body, view other patients' procedure of MRI examination so that they could truly realize the security of MRI examination. Family members were informed to accompany with the patient to enhance his/her confidence.

\subsubsection{Nursing of Systematic Desensitization}

Encouraged patients to look at the examining table and let them get on the ex- 
amining table with his/her family members accompanied. Informed methods of relaxing the whole body to those examined patients, let them close eyes and taken a deep breath. Patients were also given alarm ball to press in a time when they feel uncomfortable so that doctors and nurses could be called out.

\subsubsection{Drug Nursing}

After repeated systematic desensitization and approval el of family members, patients could be used with drugs such as alprazolam and diazepam before examination when they could not cooperate well, to getting better sedation and easing symptoms like palpitation and tumble. These methods could improve the success rate of MRI examination.

\subsubsection{Nursing in Examination}

The patient lay under scanner with the help of nurse, and his/her family member could accompany with him/her in scanning room. In the process of examination, relaxing music was used to reduce noise. The patient's eyes were covered to reduce his/her sense of oppression from surrounding environment. Communicated with the patient in order to distract his/her attention, relieve anxiety and fear and help to finish examination successfully.

\subsubsection{Nursing after Examination}

After examination, Patients were asked whether they felt uncomfortable in time, praised them to keep their psychological states well.

\subsection{Observation Targets and Criterions}

\subsubsection{The Psychological States in Two Groups}

Self-rating anxiety scale (SAS) and self-rating depression scale (SDS) were used to grade psychological states answered by claustrophobia patients themselves, with 100 scores as full score. The higher of the scores got, the worse of patients' psychological states represented.

\subsubsection{Success Rate of MRI Examination}

Finished the whole examination with excellent images represented successful.

\subsection{Statistical Analysis}

All raw data of psychological states and success rate of MRI examination in two groups were analyzed using a statistical software package of SPSS20.0. Scores of psychological states were recorded with the Mean \pm standard deviation $(\bar{\chi} \pm S)$. The chi-square test was used to evaluate the success rate between two groups. The psychological states were calculated by independent samples $T$ test between two groups. $P<0.05$ was considered statistically significant.

\section{Results}

\subsection{Psychological States}

The results were shown in Table 1 . The scores of anxiety and depression had a 
Table 1. Scores of psychological states in two groups.

\begin{tabular}{cccc}
\hline Group & Number & Anxiety(Points) & Depression(Points) \\
\hline Control group & 20 & $46.20 \pm 3.07$ & $44.30 \pm 2.54$ \\
Observation group & 20 & $37.50 \pm 2.54$ & $37.70 \pm 2.15$ \\
t value & & 9.756 & 8.870 \\
$P$ & & 0.000 & 0.000 \\
\hline
\end{tabular}

significant difference between these two groups. The psychological states in observation group were better than the control group $(P<0.05)$.

\subsection{Success Rate of MRI Examination}

n control group, 7 patients were successful. The success rate was $35 \% .18$ patients in observation group were successful with a success rate of $90 \%$. There was a significant difference between these two groups $\left(\chi^{2}=10.667, \mathrm{P}=0.001\right)$. The success rate of MRI examination in observation group was significantly higher than that of the control group.

\section{Discussion}

MRI has many advantages, such as non-radiation, non-invasion and high tissue resolution and so on. It can be used to diagnose diseases very well. The claustrophobics will lead to panic and other autonomic symptoms in an enclosed space [3]. Because the space is relatively narrow and the noise is significantly in the MRI examination, the patient will present some situations such as dizziness, pale complexion and so on. So they will have a psychological resistance to the examination, and can't stick to finish the examination. Therefore, for the claustrophobics who undergo MRI examination, the key to improving the success rate of MRI is to adjust the psychological status of the patients.

It can only eliminate some factors which affect the effects of examination with routine nursing to the claustrophobics [4]. The unhealthy psychological status for patients like anxiety and panic cannot be improved. It leads to a strong feeling with patients to avoid the examination, and the MRI examination cannot go smoothly [5] [6].

In this study, strengthened nursing interventions were taken on the basis of routine nursing, mainly including environmental and psychological nursing. In nursing interventions, the quiet and comfortable examination environment can reduce the patient's panic and eliminate the patients' pressure made by noise. The effective nursing environment can make patients feel comfortable and increase the sense of security of the patients. Health education, psychological nursing, and family support can make patients know that they are accompanied during the examination process. It will reduce the feeling of anxiety and fear. In systematic desensitization stage, it can eliminate the misgiving of patients to the examination. Drug nursing and nursing in the examination can help the patients stick to complete the examination, and can appease the emotions of patients who 
cannot finish the examination. After the examination, appeasing and praising the patients can make them improve the sense of security. Practices show that the effective nursing interventions can make patients with claustrophobia complete the examination successfully. In our study, the results demonstrated that the psychological states in observation group with strengthened nursing interventions were better than the control group $(P<0.05)$. Moreover, the success rate of MRI examination in observation group was significantly higher than that of the control group $(P<0.05)$.

In summary, strengthened nursing interventions to the claustrophobics in MRI examination can improve the psychological state of patients and enhance the success rate of MRI examination. It is crucial and necessary in routine MRI examination for patients with claustrophobia.

\section{Conflicts of Interest}

The authors declare no conflicts of interest.

\section{Funding Sources}

This research was funded by the Scientific and Technological Development Foundation of Shandong Province (grant no. 2012YD18060) and the Medicine and Health Development Foundation of Shandong Province (grant no. 2016WS0505).

\section{References}

[1] Klaming, L., van Minde, D., Weda, H., Nielsen, T. and Duijm. L.E. (2015) The Relation between Anticipatory Anxiety and Movement during an MR Examination. Academic Radiology, 22, 1571-1578. https://doi.org/10.1016/j.acra.2015.08.020

[2] Enders, J., Zimmermann, E., Rief, M., Martus, P., Klingebiel, R., Asbach, P., Klessen, C., Diederichs, G., Wagner, M., Teichgräber, U., Bengner, T., Hamm, B. and Dewey, M. (2011) Reduction of Claustrophobia with Short-Bore versus Open Magnetic Resonance Imaging: A Randomized Controlled Trial. PLoS One, 6, e23494. https://doi.org/10.1371/journal.pone.0023494

[3] Dewey, M. (2010) Claustrophobia Preventing MR Imaging of the Breast. Radiology, 256, 328-329. https://doi.org/10.1148/radiol.100113

[4] Hollenhorst, J., Münte, S., Friedrich, L., Heine, J., Leuwer, M., Becker, H. and Piepenbrock, S. (2001) Using Intranasal Midazolam Spray to Prevent Claustrophobia Induced by MR Imaging. American Journal of Roentgenology, 176, 865-868. https://doi.org/10.2214/ajr.176.4.1760865

[5] Dewey, M., Schink, T. and Dewey, C.F. (2007) Claustrophobia during Magnetic Resonance Imaging: Cohort Study in over 55,000 Patients. Journal of Magnetic Resonance Imaging, 26, 1322-1327. https://doi.org/10.1002/jmri.21147

[6] Eshed, I., Althoff, C.E., Hamm, B. and Hermann, K.G. (2007) Claustrophobia and Premature Termination of Magnetic Resonance Imaging Examinations. Journal of Magnetic Resonance Imaging, 26, 401-404. https://doi.org/10.1002/jmri.21012 
Submit or recommend next manuscript to SCIRP and we will provide best service for you:

Accepting pre-submission inquiries through Email, Facebook, LinkedIn, Twitter, etc. A wide selection of journals (inclusive of 9 subjects, more than 200 journals)

Providing 24-hour high-quality service

User-friendly online submission system

Fair and swift peer-review system

Efficient typesetting and proofreading procedure

Display of the result of downloads and visits, as well as the number of cited articles Maximum dissemination of your research work

Submit your manuscript at: http://papersubmission.scirp.org/

Or contact ym@scirp.org 